\title{
Effect of inhibition of the Ubiquitin-Proteasome System and Hsp90 on growth and survival of Rhabdomyosarcoma cells in vitro
}

\author{
Marica Peron ${ }^{1 \dagger}$, Paolo Bonvini ${ }^{1,2 \dagger}$ and Angelo Rosolen ${ }^{1 *}$
}

\begin{abstract}
Background: The ubiquitin-proteasome system (UPS) and the heat shock response (HSR) are two critical regulators of cell homeostasis, as their inhibition affects growth and survival of normal cells, as well as stress response and invasiveness of cancer cells. We evaluated the effects of the proteasome inhibitor Bortezomib and of 17-DMAG, a competitive inhibitor of Hsp90, in rhabdomyosarcoma (RMS) cells, and analyzed the efficacy of single-agent exposures with combination treatments.
\end{abstract}

Methods: To assess cytotoxicity induced by Bortezomib and 17-DMAG in RMS cells, viability was measured by MTT assay after 24, 48 and 72 hours. Western blotting and immunofluorescence analyses were carried out to elucidate the mechanisms of action. Apoptosis was measured by FACS with Annexin-V-FITC and Propidium lodide.

Results: Bortezomib and 17-DMAG, when combined at single low-toxic concentrations, enhanced growth inhibition of RMS cells, with signs of autophagy that included intensive cytoplasmic vacuolization and conversion of cytosolic LC3-I protein to its autophagosome-associated form. Treatment with lysosomal inhibitor chloroquine facilitates apoptosis, whereas stimulation of autophagy by rapamycin prevents LC3-I conversion and cell death, suggesting that autophagy is a resistance mechanism in RMS cells exposed to proteotoxic drugs. However, combination treatment also causes caspase-dependent apoptosis, PARP cleavage and Annexin V staining, as simultaneous inhibition of both UPS and HSR systems limits cytoprotective autophagy, exacerbating stress resulting from accumulation of misfolded proteins.

Conclusion: The combination of proteasome inhibitor Bortezomib with Hsp90 inhibitor 17-DMAG, appears to have important therapeutic advantages in the treatment of RMS cells compared with single-agent exposure, because compensatory survival mechanisms that occur as side effects of treatment may be prevented.

\section{Background}

Rhabdomyosarcoma (RMS) is the most common sarcoma among children and adolescents, accounting for $5 \%$ of all malignancies of these age groups. RMS can be distinguished in alveolar (ARMS), embryonal (ERMS), and the less common variant pleomorphic RMS subtypes. ARMS are more aggressive than ERMS, have a higher tendency to metastasize [1,2] and frequently localize in the extremities [3]. ERMS mainly originate in the genitourinary tract, head and neck [4] and have a

\footnotetext{
*Correspondence: angelo.rosolen@unipd.it

${ }^{\dagger}$ Equal contributors

'Clinica di Oncoematologia Pediatrica, Azienda Ospedaliera-Università di Padova, Via Giustiniani 3, Padova 35128, Italy

Full list of author information is available at the end of the article
}

better prognosis than ARMS. In 2/3 of cases ARMS cells harbour a reciprocal chromosomal translocation $\mathrm{t}(2 ; 13)$ (q35;q14) [5] that generates the chimeric transcriptional factor PAX3-FKHR, which causes aberrant gene expression in RMS cells and influences tumour aggressiveness [6].

Recently, Bortezomib and 17-DMAG have been suggested as potential new agents for the treatment of RMS, being both drugs effective at reducing RMS cell survival and invasiveness $[7,8]$. Bortezomib (Velcade ${ }^{\mathrm{TM}}$ ) is a dipeptidyl boronic acid derivative, that inhibits the chymotryptic-like activity of the $26 \mathrm{~S}$ proteasome subunit, and promotes apoptosis through $\mathrm{G}_{2} / \mathrm{M}$ cell cycle arrest, activation of stress response and impairment of NF- $\kappa B$ signalling [9]. Bortezomib-dependent inhibition

\section{Biomed Central}


of proteasome activity is a therapeutic strategy under investigation in several tumour types, used either as single agent or in combination with conventional chemotherapeutic agents [10,11]. 17-DMAG [17-(Dimethylaminoethylamino)-17-Demethoxygeldanamycin] is a soluble geldanamycin derivative [12], a benzoquinoid ansamycin antibiotic inhibitor of the Hsp90 molecular chaperone, which prevents nucleotide binding and ATPase activity of Hsp90 [13], thus impeding the correct folding of several signal transduction proteins involved in tumour cell growth and survival [14]. 17DMAG has been studied for its antitumor activity in blastomas [15], carcinomas and leukemias [16], where it caused inhibition of cell growth and survival.

We used Bortezomib and 17-DMAG as single agents or in combination and we demonstrated that when added simultaneously they induce growth inhibition and cell death in rhabdomyosarcoma cells.

\section{Methods}

\section{Cell cultures}

Human RMS cell lines RD, RH30 were maintained in RPMI 1640 medium containing $10 \%$ heat-inactivated fetal calf serum (FCS), $2 \mathrm{mmol} / \mathrm{L}$ glutamine, $100 \mathrm{U} / \mathrm{mL}$ penicillin and $100 \mu \mathrm{g} / \mathrm{mL}$ streptomycin and grown under standard tissue-culture conditions.

\section{Reagents and antibodies}

17-DMAG was purchased from Alexis (Axxora Life Science, USA), dissolved in dimethylsulfoxide (DMSO) at concentration of $10 \mathrm{mM}$ and stored at $-80{ }^{\circ} \mathrm{C}$.

Bortezomib was kindly provided by Millenium Pharmaceuticals (Millenium Pharmaceuticals, Inc. Cambridge, Massachusetts, USA). Antibodies against PARP and LC3B were purchased from Cell Signaling (Cell Signaling Technology, Inc., Danvers, Massachusetts, USA), $\beta$-actin, PMSF, chloroquine and rapamycin from SIGMA (SIGMA-Aldrich Co., St. Louis, Missouri, USA). Leupeptin and aprotinin protease inhibitors were obtained from CAPPEL (ICN Biomedicals Inc., Irvine, California, USA) and Calbiochem (Merck, Darmstadt, Germany), respectively. Acridine orange was purchased from Invitrogen (Invitrogen, Eugene, Oregon, USA), whereas DAPI nucleic acid stain, anti-tubulin antibody and fluorophoreconjugated goat anti-rabbit Alexa488 antibodies were from Molecular Probes (Invitrogen, Eugene, Oregon, USA). Horseradish peroxidase-conjugated sheep antimouse and donkey anti-rabbit antibodies were obtained from GE Healthcare (GE Healthcare Bio-Sciences AB, Uppsala, Sweden). For western blot analysis, proteins were quantified by the BCA protein assay (Pierce Chemical, Co., Rockford, Illinois, USA), transferred to nitrocellulose membranes (Schleicher \& Schuell-Whatman, Maidstone, Kent, UK), and visualized by using Chemicon chemiluminescence reagents (Chemicon International, Inc., Temecula, California, USA).

\section{Cell viability assays}

Cell viability was assessed by MTT assay. Briefly, $3 \times 10^{3}$ cells were seeded in 96-well plates and cultured in the presence or absence of the test-drugs at $37{ }^{\circ} \mathrm{C}$ for up to 72 h. MTT salt ((3-(4,5-dimethylthiazol-2-yl)-2,5-diphenyltetrazolium bromide); SIGMA Co., USA) was added for $4 \mathrm{~h}$ and reduction of MTT salt was measured at $24 \mathrm{~h}$ intervals by spectrophotometer at $540 \mathrm{~nm}$ wave-length.

To determine apoptosis, cells were treated with drugs or left untreated as indicated. After 48h-treatment, $0,5 \times 10^{6}$ cells were harvested and washed with temperate PBS. The cells were resuspended in $1 \mathrm{~mL}$ of $1 \mathrm{X}$ annexin-binding buffer (10 mM HEPES, pH 7.4; $140 \mathrm{mM} \mathrm{NaOH} ; 2.5 \mathrm{mM} \mathrm{CaCl} 2$ ), stained with $5 \mu \mathrm{l}$ annexin-V-fluorescein isothiocyanate (FITC) and $5 \mu \mathrm{l}$ of propidium iodide (PI), and then incubated for $15 \mathrm{~min}$ utes at room temperature in the dark (Immunostep Research, Salamanca, Spain). Apoptotic cells were then determined by flow cytometry, using a FACS Calibur (Becton Dickinson, Franklin Lakes, New Jersey, USA). Both early apoptotic (annexin-V-positive, PI-negative) and late apoptotic cells (annexin-V-positive, PI-positive) were analyzed. To measure autophagy, cells were stained with acridine orange (AO) to detect vesicular organelles characteristic of lysosomal activity. Briefly, cells were cultured in medium, treated as described above and $\mathrm{AO}$ was added for 15 minutes at final concentration of $5 \mu \mathrm{g} /$ $\mathrm{mL}$. Cells were analyzed and photographed by using a fluorescence microscope with a digital camera (Leica DC 300F) and by using Leica IM1000 software (Leica Mycrosystem Ltd., Wetzlar, Germany).

\section{Cell lysis, immunoblotting}

To analyze protein expression, treated and untreated cells were washed twice in $1 \mathrm{X}$ phosphate-buffered saline (PBS) and lysed in lysis buffer (50 mM Tris- $\mathrm{HCl}[\mathrm{pH}$ 7.5], $150 \mathrm{mM} \mathrm{NaCl}, 2 \mathrm{mM}$ EDTA, 0,1 \% SDS, 0,5 \% sodium deossycolate, $1 \%$ TritonX-100, 1 mM PMSF, $20 \mu \mathrm{g} / \mathrm{mL}$ aprotinin, $20 \mu \mathrm{g} / \mathrm{mL}$ leupeptin). Lysates were clarified by high-speed centrifugation (14.000 rpm, at $4{ }^{\circ} \mathrm{C}$ x $30 \mathrm{~min}$ ), and 40-60 $\mathrm{g}$ g of whole cell lysates were fractionated by SDS-PAGE. Proteins were subsequently transferred onto nitrocellulose membrane, and their expression was quantified by densitometric analysis and normalized for the expression of $\beta$-actin.

\section{Fluorescence microscopy and DAPI staining}

To analyze proteins under non-denaturant conditions, RMS cells were treated with drugs or left untreated (DMSO) and then spotted onto 12-well multitest slides (ICN Biomedicals, Inc., USA). Cells were fixed with $4 \%$ 
paraformaldehyde, permeabilized with $0.2 \%$ TritonX100 and non-specific reactivity was blocked by incubating cells with $100 \mathrm{mM}$ glycin followed by $10 \%$ FCS-PBS. Primary antibodies were added for $1 \mathrm{~h}$ at $37^{\circ} \mathrm{C}$, followed by fluorophore-conjugated secondary antibody Alexa488. Slides were washed in PBS, counter-stained with DAPI (4',6-diamidino-2-phenylindole, 1:5000) and mounted with 1:1 PBS-glycerol. Images were taken with a fluorescence microscope equipped with a digital camera (Leica DC 300F) and analyzed by using Leica IM1000 software (Leica Mycrosystem Ltd., Germany).

\section{Data analysis}

Results were expressed as mean \pm standard deviation (SD) of three independent experiments and analyzed by using the two-sided Student's $t$ test, with a P value $<0.05$ considered significant.

\section{Results}

\section{Combinatorial exposure of RMS cells to Bortezomib and} 17-DMAG

To assess the optimal conditions for combinatorial use of Bortezomib and 17-DMAG in rhabdomyosarcoma tumour cells, the effects of Bortezomib and 17-DMAG as single agents were first investigated in ERMS (RD) and ARMS (RH30) cell lines, and cell viability was measured at increasing time points. In these conditions, Bortezomib and 17-DMAG inhibited proliferation of both RH30 and RD cells in a time- and dose-dependent manner, although embryonal RD cells resulted more sensitive to treatments, with a reduction in cell survival of up to $80 \%$ after 72 hours with either Bortezomib $(50 \mathrm{nM}$ IC50 $=7.5 \mathrm{nM})$ or 17-DMAG $(100 \mathrm{nM}$ IC50 $=35 \mathrm{nM})$ (Figure 1A). Drug treatments were less effective in alveolar RH30 cells, as indicated by both the higher IC50 values (Bortezomib $\mathrm{IC}_{50}=14 \mathrm{nM}$; 17-DMAG $\mathrm{IC}_{50}=45$ $\mathrm{nM}$ ) and the survival rate observed. Therefore, cytotoxicity of the Bortezomib/17-DMAG combination was assessed by using multiple drug concentrations and time points. Under these conditions, Bortezomib and 17DMAG added simultaneously increased drug-induced growth inhibition of both cell lines, and the effect correlated with time exposure (Figure 1B). Combinations of low doses of Bortezomib (5-7.5nM) with cytostatic concentrations of 17-DMAG $(\leq 50 \mathrm{nM})$ (open arrowheads) were more effective than each compound used alone (closed arrowheads), whereas at higher concentrations (Bortezomib 20-50nM; 17-DMAG 100nM) cytotoxicity was independent of treatment modality (Figure $1 \mathrm{~B}$ and 1C). In this context, Bortezomib/17-DMAG combination treatment was able to overcome the lower sensitivity of RH30 ARMS cells to proteasome inhibition, resulting more effective at inhibiting cell growth and survival than single-agent treatment.

\section{Simultaneous induction of apoptosis and autophagy in RMS cells}

Consistent with combination treatment results, $7.5 \mathrm{nM}$ Bortezomib and 50nM 17-DMAG were chosen as suitable concentrations to study the relationship between growth inhibition and survival, and to determine whether cross-talk between pathways influence RMS cell fate in the setting of proteotoxic stress. In this context, it was previously shown that proteasome inhibitors interfere with protein degradation and increase the amount of toxic aggregates in the cytoplasm [17-19], whereas heat shock protein inhibitors activate the unfolded protein response (UPR) pathway but also stimulate autophagy to maintain cell homeostasis [20-23]. Autophagy is an important mechanism for the removal of damaged cytoplasmatic components after cellular stress, but it can also lead to cell death in collaboration with several apoptogenic factors [24]. Therefore, to better understand the mechanisms that lead to growth inhibition and cell death of RMS cells in the presence of the Bortezomib/ 17-DMAG combination, we measured the levels of apoptosis and autophagy by monitoring both PARP cleavage and LC3 processing, respectively. When autophagy is upregulated, cytosolic LC3-I protein is cleaved and recruited to autophagosome membranes (LC3-II) [25], where it drives autophagic vacuoles formation before lysosomemediated proteolysis occurs [26]. Consistent with these findings, we observed that in these settings PARP cleavage occurred in RH30 exposed to 17-DMAG, whereas in ERMS RD cells apoptosis was induced by Bortezomib (Figure 2A). In both cell lines, the induction of apoptosis correlated with the conversion of endogenous LC3 protein from cytosolic LC3-I to the autophagosome-associated LC3-II form, and this occurred together with the accumulation of perinuclear vacuoles inside cells in the absence of a clear apoptotic morphology (Figure 2B, upper and lower panels). For further analysis of autophagy we used the lysosotropic compound acridine orange, measuring $\mathrm{AO}$ bright green-to-red fluorescence transition in acidic vesicles forming during autophagy [26]. Consistent with LC3II accumulation, staining with acridine orange dye revealed an increase of red fluorescence in RD cells after treatment with Bortezomib, whereas red fluorescence in RH30 cells increased only after 17-DMAG exposure (Figure 2C). Treatment with both Bortezomib and 17DMAG enhanced the amount of acidic vacuoles in either RH30 or RD cells, which was abrogated by the addition of chloroquine lysosomal inhibitor (Figure 2C). By interfering with luminal $\mathrm{pH}$, chloroquine suppresses downstream lysosome-mediated autophagic degradation, whereas rapamycin, by stimulating both expression and processing of LC3- I, exerts an opposite effect and induces autophagy [27]. In addition, chloroquine in combination with proteasome inhibitors can enhance caspase-mediated 


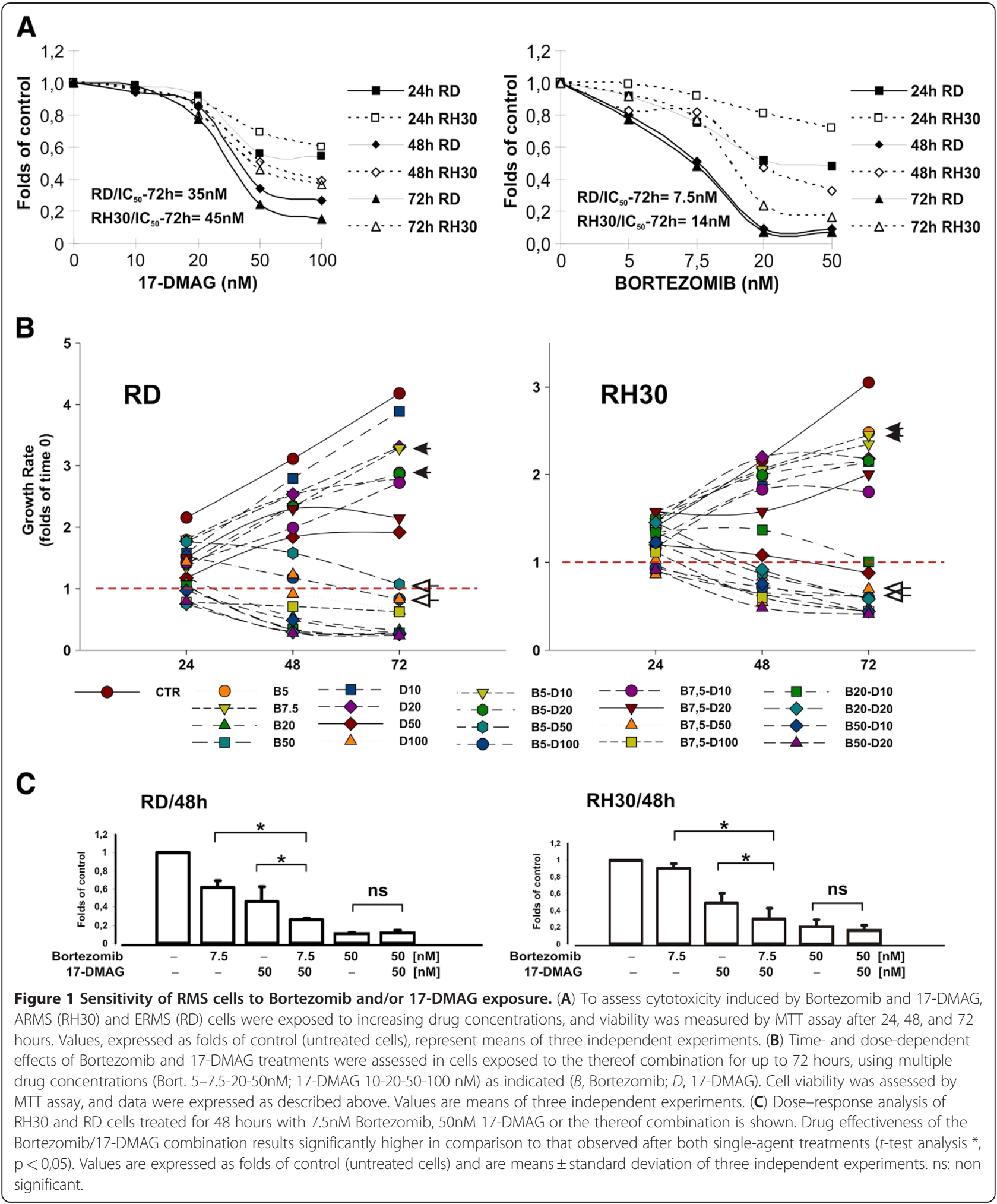

apoptosis [28], whereas rapamycin when used in combination treatments reduces the accumulation of toxic poliubiquitinated aggregates and attenuates drug-induced cell death $[29,30]$. Therefore, the response pattern to Bortezomib and 17- DMAG of rhabdomyosarcoma cells was investigated in conditions of autophagy 


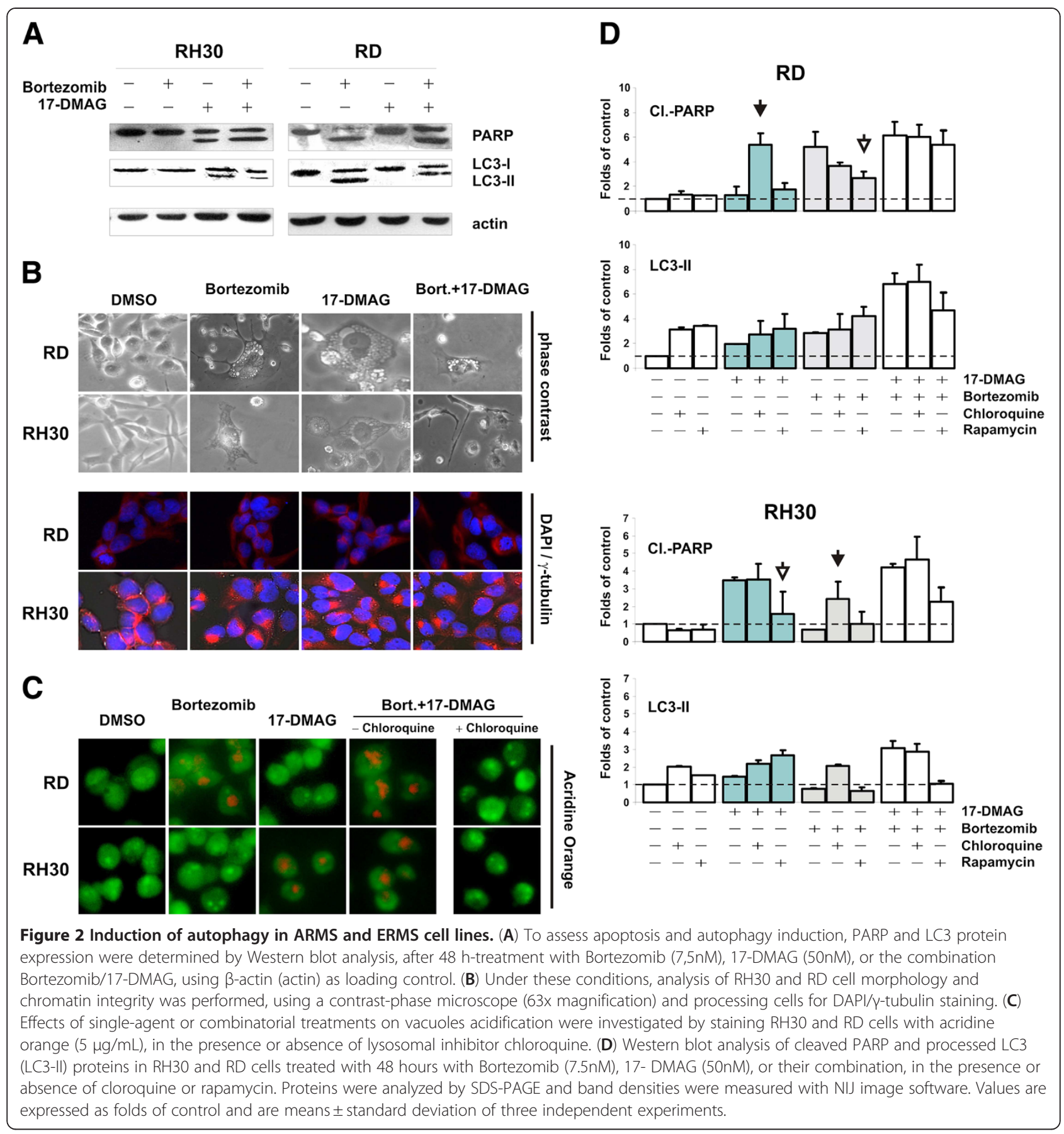

induction or repression, by adding to drug-treated and untreated cells rapamycin and chloroquine, respectively. We found that PARP cleavage increased in drug-treated $\mathrm{RD}$ and RH30 cells in the presence of chloroquine, but not after the addition of rapamycin (Figure 2D). In particular, suppression of autophagy by chloroquine correlated with the accumulation of cleaved PARP in cells not sensitive to either proteasome or Hsp90 inhibitors (i.e. RH30/Bortezomib and RD/17-DMAG, closed arrowheads), whereas stimulation of autophagy by rapamycin exerted the opposite effect primarily in cells that were sensitive to single agent treatments (RD/Bortezomib and RH30/17-DMAG, open arrowheads). In contrast, LC3-I processing in response to single agent treatments varied less significantly, as well as PARP cleavage in cells treated with the Bortezomib/17-DMAG combination (Figure 2D), suggesting that alteration of lysosomal function may be critical for cell survival at the early onset of stress response, but not following severe stress induction in late apoptosis. 


\section{Autophagy as a pro-survival mechanism in apoptotic rhabdomyosarcoma cells}

The balance between apoptosis and autophagy is important in tumour development, but also for response to therapy, since in addition to their unique role in suppressing and promoting tumorigenesis, respectively, apoptosis and autophagy may contribute to drug sensitivity when interfacing to each other. To investigate further the involvement of autophagy in drug-induced apoptosis and cell survival, Annexin V/Propidium Iodide (AV/PI) double staining analysis was performed in rhabdomyosarcoma cells exposed to Bortezomib, 17DMAG, or both, in the presence or absence of rapamycin. Consistent with previous findings, survival of RH30 and RD cells was significantly reduced by the Bortezomib/17-DMAG combination (Figure 3, panels, RH30/ $\mathrm{AV}^{-} / \mathrm{PI}^{-}=44.7 \% ; \mathrm{RD} / \mathrm{AV}^{-} / \mathrm{PI}^{-}=56 \%$ ) compared with control and single-agent treatments. This was accompanied by increased apoptosis (Figure 3, panels and histograms aside, $\mathrm{RH} 30 / \mathrm{AV}^{+}=47.3 \% ; \mathrm{RD} / \mathrm{AV}^{+}=37 \%$ ), whereas necrosis was not significantly induced (panels, $\mathrm{RH} 30 / \mathrm{PI}^{+}=8 \%$; $\mathrm{RD} / \mathrm{PI}^{+}=7 \%$, respectively). Importantly, pre-treatment with non-toxic concentrations of rapamycin partially suppressed apoptotic cell death caused by combined exposure to Bortezomib and 17-DMAG (Figure 3, panels and histograms), therefore supporting the notion that drug-induced autophagy may act as a compensatory mechanism in rhabdomyosarcoma tumour cells that mitigates stress response and contributes to apoptosis resistance.

\section{Discussion}

The heat shock proteins (HSP) and the ubiquitinproteasome system (UPS) contribute to maintain protein homeostasis in eukaryotic cells. They have been recently proposed as therapeutic targets in a wide variety of cancers [31,32]. Preclinical studies have demonstrated the antitumour activity of proteasome inhibitors in childhood sarcomas, including rhabdomyosarcoma, Ewing sarcoma (EWS) and osteosarcoma (OS) [7,33-36]. In

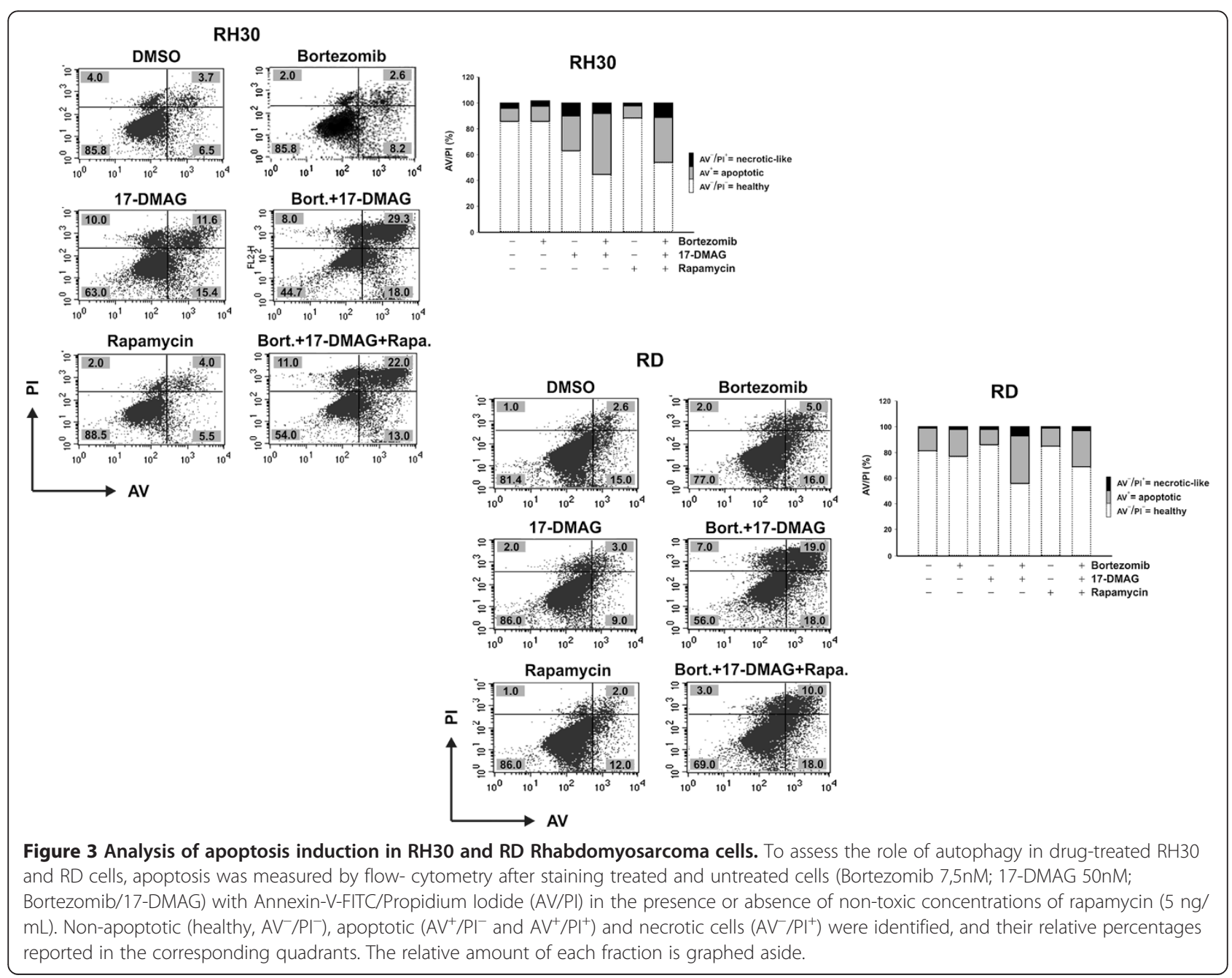


addition, when used in combination with standard chemotherapeutic agents or targeted therapeutics, proteasome inhibitors can increase anti-tumor activity, suggesting that combination therapy can achieve better results than single-agent treatments [37,38]. Because several Hsp90 client proteins are relevant for tumour growth and survival, inhibition of Hsp90 has also been investigated in cancer, including rhabdomyosarcomas, demonstrating that targeting Hsp90 may reduce tumour cell proliferation and migration, both in vivo and in vitro [8,12]. Targeting the Hsp90 molecular chaperone has shown anti-tumor efficacy in Ewing sarcomas, whereas the efficacy in childhood osteosarcoma is lower and limited to specific treatment modalities $[12,39,40]$. Similarly to proteasome inhibitors, preclinical and clinical studies in haematological malignancies have demonstrated that Hsp90 inhibitors are effective as anti-cancer drugs especially when combined with conventional chemotherapy or targeted therapeutics [41-44]. Based on these observations, we investigated the antitumour activity of Bortezomib and the Hsp90 inhibitor 17-DMAG in rhabdomyosarcoma cells, comparing single-agent exposures with combination treatments. Consistent with previous findings $[7,8]$, both Bortezomib and 17-DMAG were highly efficient at inhibiting growth and survival of RMS cells. Embryonal RD cells were more sensitive than alveolar RH30 cells to singleagent exposure, although such a different sensitivity was not justified by the expression of specific target proteins, like heat shock proteins, cell cycle inhibitors and proapoptotic factors $[45,46]$. Conversely, effectiveness of the combined treatment was comparable among cell lines, including RH30 cells that responded poorly to Bortezomib alone. Combination of Bortezomib and 17-DMAG induced autophagy in addition to apoptosis, and this was confirmed by the concurrent cleavage of LC3-II and PARP proteins.

Consistent with these findings, inhibition of proteasome activity causes the accumulation of misfolded proteins inside cells, which bind to heat shock proteins in discrete structures known as aggresomes and are subsequently degraded by lysosomes [47]. Attachment of ubiquitin to proteins, in fact, not only constitutes a degradation signal for the proteasome, but also serves for removal of proteins by lysosome-mediated autophagy [48]. In these conditions, unfolded proteins are delivered to lysosomes by heat shock proteins, in what is known as chaperone-mediated autophagy (CMA) [23,49-52]. Macroautophagy, the most important lysosomemediated type of autophagy, does not usually need shuttling substrate proteins by heat shock proteins, but recent evidences suggest that in some cases heat shock proteins translocate ubiquitinated proteins into lysosomes and assist their autophagic degradation as well $[48,53]$. Collectively, these findings indicate that autophagy may be activated by proteasome inhibitors, likely as a response mechanism that alleviates from stress and protects cells from apoptosis [19,54-56]. Consistent with this scenario we demonstrated that autophagy is activated in rhabdomyosarcoma cells to withstand drug-induced cytotoxicity, as suggested by LC3-I activation and intensive cytoplasmic vacuolization. As expected, the inhibition of autophagy by chloroquine increases caspase-dependent PARP cleavage in rhabdomyosarcoma stressed cells, whereas its induction by rapamycin partially rescued cells from drug-induced apoptosis. In particular, inhibition of apoptosis occurs when cells are pretreated with rapamycin prior to administering Bortezomib and/or 17-DMAG, whereas the inhibition of autophagy increases cell death when induced together with both proteasome and Hsp90 inhibition. This suggests that RMS cells may activate autophagy as cytoprotective response to drug treatment, and the inhibition of autophagy enhances sensitivity of RMS cells to anti-cancer drugs, including Hsp90 and proteasome inhibitors. Of note, inhibition of autophagy is more effective at early onset of stress response than following apoptosis induction, providing evidence that autophagy occurs before cell death and it functions primarily as a cell survival mechanism.

The ubiquitin-proteasome and autophagy-lysosome are often considered distinct degradation systems. However, recent studies suggest that these two pathways are mechanistically linked [53,56], as proteasome inhibition induces autophagy when removal of toxic polyubiquitinated aggregates is necessary for cell survival, while proteasome activity is induced when formation and activity of lysosomes are impaired. Autophagy and apoptosis are events regulated by common survival pathways, including the JNK1, Bcl-2 and the PI3K/AKT signaling pathway. It has been shown that JNK-dependent phosphorylation of $\mathrm{Bcl}-2$ promotes cell survival by disrupting Bcl-2 binding to Beclin-1 and activates autophagy, whereas sustained $\mathrm{Bcl}-2$ phosphorylation blocks $\mathrm{Bcl}-2$ anti-apoptotic activity and apoptosis overwhelms autophagy $[57,58]$. AKT phosphorylates and prevents Bad pro-apoptotic activity and inhibits autophagy by impairing TSC1TSC2 tumor suppressor proteins activity [59]. Of note, JNK and AKT are, among survival proteins, mostly affected in rhabdomyosarcoma cells treated with proteasome and Hsp90 inhibitors, but their involvement in drug-induced autophagy have not been investigated yet $[7,8,60]$.

Nevertheless, our findings suggest that combination treatment with Bortezomib and 17-DMAG can overcome autophagy, a mechanism protecting rhabdomyosarcoma cells from drug-induced cytotoxicity. Further studies are warranted on the use of low concentrations of proteasome inhibitors in combination with Hsp90 inhibitors, both in vitro and in vivo, as they might represent a tool capable of counteracting protective mechanisms, such as 
autophagy, that may affect treatment efficacy and, ultimately, the outcome of RMS patients.

\section{Conclusions}

Our study showed that the combination of Bortezomib with 17-DMAG exerts more potent inhibitory effects on RMS cell growth than each agent alone. Combination treatment has important therapeutic advantages because it counteracts survival mechanisms that occur as side effects of treatment. These results may contribute to new therapeutic approaches in rhabdomyosarcoma.

\section{Abbreviations \\ 17-DMAG: [17-(Dimethylaminoethylamino)-17-Demethoxygeldanamycin]; AO: Acridine Orange; ARMS: Alveolar Rhabdomyosarcoma; AV: Annexin V- FITC; BZ: Bortezomib; CMA: Chaperone Mediated Autophagy; ERMS: Embrional Rhabdomyosarcoma; Hsp90: Heat Shock Protein 90; HSR: Heat Shock Response; LC3: Light Chain 3; MTT: 3-(4,5-dimethylthiazol-2- yl)-2,5-diphenyltetrazolium bromide; PI: Propidium lodide; \\ RMS: Rhabdomyosarcoma; UPR: Unfolded Protein Response; UPS: Ubiquitin- Proteasome System.}

\section{Competing interests}

The authors declare that they have no competing interests.

\section{Authors' contributions}

MP and PB designed and conducted the study and analyzed the data. AR designed the study and coordinated all aspects of the project. All authors contributed to write, read and approve the manuscript in the final form.

\section{Acknowledgment}

This work was funded by MIUR-2010, Associazione Italiana per la Ricerca sul Cancro (AIRC) and by Fondazione Città della Speranza.

\section{Author details}

'Clinica di Oncoematologia Pediatrica, Azienda Ospedaliera-Università di Padova, Via Giustiniani 3, Padova 35128, Italy. ${ }^{2}$ Fondazione Città della Speranza, Via del Lavoro 12, Malo-Vicenza 36034, Italy.

Received: 10 November 2011 Accepted: 21 May 2012 Published: 12 June 2012

\section{References}

1. Wachtel M, Runge T, Leuschner I, Stegmaier S, Koscielniak E, Treuner J, Odermatt B, Behnke S, Niggli FK, Schafer BW: Subtype and prognostic classification of rhabdomyosarcoma by immunohistochemistry. J Clin Oncol 2006, 24(5):816-822.

2. Merlino G, Helman L: Rhabdomyosarcoma-working out the pathways. Oncogene 1999, 18(38):5340-5348

3. Harms D: Alveolar rhabdomyosarcoma: a prognostically unfavorable rhabdomyosarcoma type and its necessary distinction from embryonal rhabdomyosarcoma. Curr Top Pathol 1995, 89:273-296.

4. Newton WA Jr, Soule EH, Hamoudi AB, Reiman HM, Shimada H, Beltangady M, Maurer H: Histopathology of childhood sarcomas, Intergroup Rhabdomyosarcoma Studies I and II: clinicopathologic correlation. J Clin Oncol 1988, 6(1):67-75.

5. Davis RJ, D'Cruz CM, Lovell MA, Biegel JA, Barr FG: Fusion of PAX7 to FKHR by the variant $\mathrm{t}(1 ; 13)(\mathrm{p} 36 ; \mathrm{q} 14)$ translocation in alveolar rhabdomyosarcoma. Cancer Res 1994, 54(11):2869-2872.

6. Bennicelli JL, Edwards RH, Barr FG: Mechanism for transcriptional gain of function resulting from chromosomal translocation in alveolar rhabdomyosarcoma. Proc Natl Acad Sci U S A 1996, 93(11):5455-5459.

7. Bersani F, Taulli R, Accornero P, Morotti A, Miretti S, Crepaldi T, Ponzetto C Bortezomib-mediated proteasome inhibition as a potential strategy for the treatment of rhabdomyosarcoma. Eur J Cancer 2008, 44(6):876-884.

8. Lesko E, Gozdzik J, Kijowski J, Jenner B, Wiecha O, Majka M: HSP90 antagonist, geldanamycin, inhibits proliferation, induces apoptosis and blocks migration of rhabdomyosarcoma cells in vitro and seeding into bone marrow in vivo. Anticancer Drugs 2007, 18(10):1173-1181.

9. Adams J: The proteasome: a suitable antineoplastic target. Nat Rev Cancer 2004, 4(5):349-360

10. Milano A, laffaioli RV, Caponigro F: The proteasome: a worthwhile target for the treatment of solid tumours?. Eur J Cancer 2007, 43(7):1125-1133.

11. Hideshima T, Richardson P, Chauhan D, Palombella VJ, Elliott PJ, Adams J, Anderson KC: The proteasome inhibitor PS-341 inhibits growth, induces apoptosis, and overcomes drug resistance in human multiple myeloma cells. Cancer Res 2001, 61(7):3071-3076.

12. Smith V, Sausville EA, Camalier RF, Fiebig HH, Burger AM: Comparison of 17-dimethylaminoethylamino-17-demethoxy-geldanamycin (17DMAG) and 17-allylamino-17-demethoxygeldanamycin (17AAG) in vitro: effects on Hsp90 and client proteins in melanoma models. Cancer Chemother Pharmacol 2005, 56(2):126-137.

13. Neerken S, Ma YZ, Aschenbrucker J, Schmidt KA, Nowak FR, Permentier HP Aartsma TJ, Gillbro T, Amesz J: Kinetics of absorbance and anisotropy upon excited state relaxation in the reaction center core complex of a green sulfur bacterium. Photosynth Res 2000, 65(3):261-268.

14. Ochel HJ, Eichhorn K, Gademann G: Geldanamycin: the prototype of a class of antitumor drugs targeting the heat shock protein 90 family of molecular chaperones. Cell Stress Chaperones 2001, 6(2):105-112.

15. Kim S, Kang J, Hu W, Evers BM, Chung DH: Geldanamycin decreases Raf-1 and Akt levels and induces apoptosis in neuroblastomas. Int $J$ Cancer 2003, 103(3):352-359.

16. Whitesell L, Lindquist SL: HSP90 and the chaperoning of cancer. Nat Rev Cancer 2005, 5(10):761-772

17. Mimnaugh EG, Xu W, Vos M, Yuan X, Isaacs JS, Bisht KS, Gius D, Neckers L: Simultaneous inhibition of hsp 90 and the proteasome promotes protein ubiquitination, causes endoplasmic reticulumderived cytosolic vacuolization, and enhances antitumor activity. Mol Cancer Ther 2004, 3(5):551-566.

18. Pandey UB, Nie Z, Batlevi Y, McCray BA, Ritson GP, Nedelsky NB, Schwartz SL, DiProspero NA, Knight MA, Schuldiner O, et al: HDAC6 rescues neurodegeneration and provides an essential link between autophagy and the UPS. Nature 2007, 447(7146):859-863.

19. Palacios C, Martin-Perez R, Lopez-Perez Al, Pandiella A, Lopez-Rivas A: Autophagy inhibition sensitizes multiple myeloma cells to17dimethylaminoethylamino-17-demethoxygeldanamycin-induced apoptosis. Leuk Res, 34(11):1533-1538

20. Finn PF, Mesires NT, Vine M, Dice JF: Effects of small molecules on chaperone-mediated autophagy. Autophagy 2005, 1(3):141-145.

21. Kaushik S, Massey AC, Mizushima N, Cuervo AM: Constitutive activation of chaperone- mediated autophagy in cells with impaired macroautophagy. Mol Biol Cell 2008, 19(5):2179-2192.

22. Massey AC, Kaushik S, Sovak G, Kiffin R, Cuervo AM: Consequences of the selective blockage of chaperone-mediated autophagy. Proc Natl Acad Sci U S A 2006, 103(15):5805-5810.

23. Li W, Yang Q, Mao Z: Chaperone-mediated autophagy: machinery, regulation and biological consequences. Cell Mol Life Sci 2011, 68(5):749-763.

24. Nikaido T, Takada T, Kitasako Y, Ogata M, Shimada Y, Yoshikawa T, Nakajima M, Otsuki M, Tagami J, Burrow MF: Retrospective study of five-year clinical performance of direct composite restorations using a self-etching primer adhesive system. Dent Mater J 2006, 25(3):611-615.

25. Kabeya Y, Mizushima N, Ueno T, Yamamoto A, Kirisako T, Noda T, Kominami E, Ohsumi Y, Yoshimori T: LC3, a mammalian homologue of yeast Apg8p, is localized in autophagosome membranes after processing. EMBO $\mathrm{J}$ 2000, 19(21):5720-5728.

26. Klionsky DJ, Abeliovich $\mathrm{H}$, Agostinis $\mathrm{P}$, Agrawal DK, Aliev G, Askew DS, Baba M, Baehrecke EH, Bahr BA, Ballabio A, et al: Guidelines for the use and interpretation of assays for monitoring autophagy in higher eukaryotes. Autophagy 2008, 4(2):151-175.

27. Martin DE, Hall MN: The expanding TOR signaling network. Curr Opin Cell Biol 2005, 17(2):158-166.

28. Qiao L, Zhang J: Inhibition of lysosomal functions reduces proteasomal activity. Neurosci Lett 2009, 456(1):15-19.

29. Pan T, Kondo S, Zhu W, Xie W, Jankovic J, Le W: Neuroprotection of rapamycin in lactacystin-induced neurodegeneration via autophagy enhancement. Neurobiol Dis 2008, 32(1):16-25.

30. Du Y, Yang D, Li L, Luo G, Li T, Fan X, Wang Q, Zhang X, Wang Y, Le W: An insight into the mechanistic role of p53-mediated autophagy induction 
in response to proteasomal inhibition-induced neurotoxicity. Autophagy 2009, 5(5):663-675.

31. Cullinan SB, Whitesell L: Heat shock protein 90: a unique chemotherapeutic target. Semin Oncol 2006, 33(4):457-465.

32. Montagut C, Rovira A, Albanell J: The proteasome: a novel target for anticancer therapy. Clin Trans/ Oncol 2006, 8(5):313-317.

33. Lauricella M, D'Anneo A, Giuliano M, Calvaruso G, Emanuele S, Vento R, Tesoriere G: Induction of apoptosis in human osteosarcoma Saos-2 cells by the proteasome inhibitor MG132 and the protective effect of pRb. Cell Death Differ 2003, 10(8):930-932.

34. Lu G, Punj V, Chaudhary PM: Proteasome inhibitor Bortezomib induces cell cycle arrest and apoptosis in cell lines derived from Ewing's sarcoma family of tumors and synergizes with TRAIL. Cancer Biol Ther 2008, 7(4):603-608

35. Yan XB, Yang DS, Gao X, Feng J, Shi ZL, Ye Z: Caspase-8 dependent osteosarcoma cell apoptosis induced by proteasome inhibitor MG132. Cell Biol Int 2007, 31(10):1136-1143.

36. Maki RG, Kraft AS, Scheu K, Yamada J, Wadler S, Antonescu CR, Wright JJ, Schwartz GK: A multicenter Phase II study of bortezomib in recurrent or metastatic sarcomas. Cancer 2005, 103(7):1431-1438.

37. Gerecitano J, Portlock C, Hamlin P, Moskowitz CH, Noy A, Straus D, Schulman P, Dumitrescu O, Sarasohn D, Pappanicholaou J, et al: Phase I trial of weekly and twiceweekly bortezomib with rituximab, cyclophosphamide, and prednisone in relapsed or refractory non-hodgkin lymphoma. Clin Cancer Res 2011, 17(8):2493-2501.

38. Furman RR, Martin P, Ruan J, Cheung YK, Vose JM, LaCasce AS, Elstrom R, Coleman M, Leonard JP: Phase 1 trial of bortezomib plus R-CHOP in previously untreated patients with aggressive non-Hodgkin lymphoma. Cancer 2010, 116(23):5432-5439.

39. Bagatell R, Beliakoff J, David CL, Marron MT, Whitesell L: Hsp90 inhibitors deplete key anti-apoptotic proteins in pediatric solid tumor cells and demonstrate synergistic anticancer activity with cisplatin. Int J Cancer 2005, 113(2):179-188.

40. Martins AS, Ordonez JL, Garcia-Sanchez A, Herrero D, Sevillano V, Osuna D, Mackintosh C, Caballero G, Otero AP, Poremba C, et al: A pivotal role for heat shock protein 90 in Ewing sarcoma resistance to anti-insulin-like growth factor 1 receptor treatment: in vitro and in vivo study. Cancer Res 2008, 68(15):6260-6270.

41. Richardson PG, Mitsiades CS, Laubach JP, Lonial S, Chanan-Khan AA, Anderson KC: Inhibition of heat shock protein 90 (HSP90) as a therapeutic strategy for the treatment of myeloma and other cancers. $\mathrm{Br}$ $J$ Haematol 2011, 152(4):367-379.

42. Duus J, Bahar HI, Venkataraman G, Ozpuyan F, Izban KF, Al-Masri H, Maududi T, Toor A, Alkan S: Analysis of expression of heat shock protein90 (HSP90) and the effects of HSP90 inhibitor (17-AAG) in multiple myeloma. Leuk Lymphoma 2006, 47(7):1369-1378.

43. Roue G, Perez-Galan P, Mozos A, Lopez-Guerra M, Xargay-Torrent S, Rosich L, Saborit- Villarroya I, Normant E, Campo E, Colomer D: The Hsp90 inhibitor IPI-504 overcomes bortezomib resistance in mantle cell lymphoma in vitro and in vivo by down-regulation of the prosurvival ER chaperone BiP/Grp78. Blood 2011, 117(4):1270-1279.

44. Sydor JR, Normant E, Pien CS, Porter JR, Ge J, Grenier L, Pak RH, Ali JA, Dembski MS, Hudak J, et al: Development of 17-allylamino-17-demethoxygeldanamycin hydroquinone hydrochloride (IPI 504), an anti-cancer agent directed against Hsp90. Proc Natl Acad Sci U S A 2006, 103(46):17408-17413.

45. Smith MA, Morton CL, Phelps DA, Kolb EA, Lock R, Carol H, Reynolds CP, Maris JM, Keir ST, Wu J, et al: Stage 1 testing and pharmacodynamic evaluation of the HSP90 inhibitor alvespimycin (17-DMAG, KOS-1022) by the pediatric preclinical testing program. Pediatr Blood Cancer 2008, 51(1):34-41.

46. Houghton PJ, Morton CL, Kolb EA, Lock R, Carol H, Reynolds CP, Keshelava $\mathrm{N}$, Maris JM, Keir ST, Wu J, et al: Initial testing (stage 1) of the proteasome inhibitor bortezomib by the pediatric preclinical testing program. Pediatr Blood Cancer 2008, 50(1):37-45.

47. Fratta P, Engel WK, McFerrin J, Davies KJ, Lin SW, Askanas V: Proteasome inhibition and aggresome formation in sporadic inclusion-body myositis and in amyloid-beta precursor protein-overexpressing cultured human muscle fibers. Am J Pathol 2005, 167(2):517-526.

48. Kirkin V, McEwan DG, Novak I, Dikic I: A role for ubiquitin in selective autophagy. Mol Cell 2009, 34(3):259-269.
49. Agarraberes FA, Dice JF: A molecular chaperone complex at the lysosomal membrane is required for protein translocation. J Cell Sci 2001, 114(Pt 13):2491-2499.

50. Salvador N, Aguado C, Horst M, Knecht E: Import of a cytosolic protein into lysosomes by chaperone-mediated autophagy depends on its folding state. J Biol Chem 2000, 275(35):27447-27456.

51. Majeski AE, Dice JF: Mechanisms of chaperone-mediated autophagy. Int J Biochem Cell Biol 2004, 36(12):2435-2444.

52. Bandyopadhyay U, Kaushik S, Varticovski L, Cuervo AM: The chaperonemediated autophagy receptor organizes in dynamic protein complexes at the lysosomal membrane. Mol Cell Biol 2008, 28(18):5747-5763.

53. Lamark T, Johansen T: Autophagy: links with the proteasome. Curr Opin Cell Biol 2010, 22(2):192-198.

54. Wu WK, Wu YC, Yu L, Li ZJ, Sung JJ, Cho CH: Induction of autophagy by proteasome inhibitor is associated with proliferative arrest in colon cancer cells. Biochem Biophys Res Commun 2008, 374(2):258-263.

55. Ge PF, Zhang JZ, Wang XF, Meng FK, Li WC, Luan YX, Ling F, Luo YN: Inhibition of autophagy induced by proteasome inhibition increases cell death in human SHG-44 glioma cells. Acta Pharmacol Sin 2009, 30(7):1046-1052.

56. Ding WX, Ni HM, Gao W, Chen X, Kang JH, Stolz DB, Liu J, Yin XM: Oncogenic transformation confers a selective susceptibility to the combined suppression of the proteasome and autophagy. Mol Cancer Ther 2009, 8(7):2036-2045.

57. Levine B, Kroemer G: Autophagy in the pathogenesis of disease. Cell 2008, $132(1): 27-42$.

58. Wei Y, Sinha S, Levine B: Dual role of JNK1-mediated phosphorylation of $\mathrm{BCl}-2$ in autophagy and apoptosis regulation. Autophagy 2008, 4(7):949-951.

59. Diaz-Troya S, Perez-Perez ME, Florencio FJ, Crespo JL: The role of TOR in autophagy regulation from yeast to plants and mammals. Autophagy 2008, 4(7):851-865.

60. Araki M, Motojima K: Hydrophobic statins induce autophagy in cultured human rhabdomyosarcoma cells. Biochem Biophys Res Commun 2008, 367(2):462-467.

doi:10.1186/1471-2407-12-233

Cite this article as: Peron et al:: Effect of inhibition of the Ubiquitin-

Proteasome System and Hsp90 on growth and survival of

Rhabdomyosarcoma cells in vitro. BMC Cancer 2012 12:233.

\section{Submit your next manuscript to BioMed Central and take full advantage of:}

- Convenient online submission

- Thorough peer review

- No space constraints or color figure charges

- Immediate publication on acceptance

- Inclusion in PubMed, CAS, Scopus and Google Scholar

- Research which is freely available for redistribution 